\title{
КАРДИОВАСКУЛЯРНЫЙ РИСК И ЕГО ВЗАИМОСВЯЗЬ С КРИТЕРИЯМИ ФЕНОТИПОВ ОЖИРЕНИЯ У ЖЕНЩИН РАЗНЫХ ВОЗРАСТНЫХ ГРУПП
}

\author{
Лясникова М.Б., Белякова Н.А., Милая Н.О., Силкина М.И., Куликова А.С. \\ ФГБОУ ВО «Терской государственный медицинский университет» Минздрава России, Тверь
}

\begin{abstract}
АКТУАЛЬНОСТЬ: в настоящее время имеются данные о том, что в ряде случаев ожирение может быть «здоровым» и не оказывать влияния на сердечно-сосудистые риски, однако, единого мнения о том, что считать метаболически здоровым ожирением не существует. В 2017 году были опубликованы национальные клинические рекомендации посвященные диагностике, лечению и профилактике ожирения и ассоциированных с ним заболеваний. Согласно им классификация с оценкой метаболического фенотипа важна, так как позволяет провести стратификацию пациентов по кардиоваскулярному риску.
\end{abstract}

ЦЕЛЬ: оценить индекс висцерального ожирения (ИВО), как признак кардиоваскулярного риска, и его корреляцию с критериями фенотипов ожирения у женщин разных возрастных групп.

МАТЕРИАЛЫ И МЕТОДЫ: бЫли обследованы женщины молодого возраста (154 пациентки

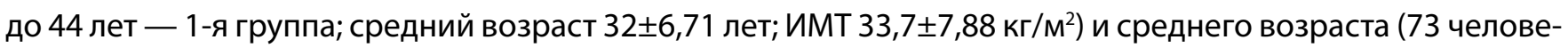

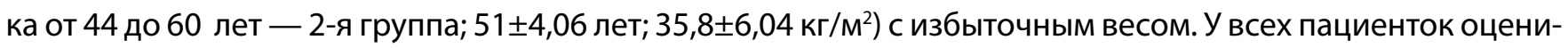
ли ИВО и его взаимосвязь, с помощью критерия Спирмена (rs), с критериями фенотипов ожирения: ОТ/ОБ, ОТ, индексом инсулинорезистентности (ИР, НОМА-IR), процентом жировой массы (ЖМ\%), глюкозой (ГЛ), триглицеридами (ТГ), ХС ЛПВП, артериальным давлением (АД АД $)$, а также с другими липидами:ХС ЛПНП, ХС ЛПОНП и трансаминазами (АСТ, АЛТ, гамма-ГТ), отражающими функцию печени.

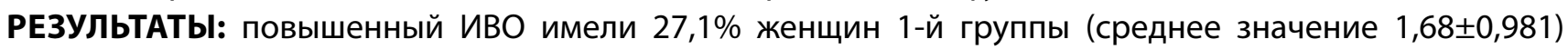
и 28,6\% - 2-й группы $(1,79 \pm 1,179)$. У молодых пациенток была выявлена прямая слабее средней корреляция ИВО с ИМТ ( $r s=0,33 ; p<0,05)$, ГЛ ( $r s=0,37 ; p<0,05)$, ХС ЛПНП ( $r s=0,38 ; p<0,05)$, средняя с ИР ( $r s=0,47$; $p<0,05)$, ОТ ( $r s=0,53 ; p<0,05)$, ХС ЛПОНП ( $r s=0,54 ; p<0,05)$, АЛТ ( $r s=0,56 ; p<0,05)$, обратная выше средней $\mathrm{CXC}$ ЛПВП (rs=-0,65; $p<0,05)$ и сильная прямая с ТГ $(r s=0,88 ; p<0,05)$. У женщин 2-й группы ИВО не был связан с антропометрическими показателями, но имел корреляцию с лабораторными показателями: обратную среднюю с XС ЛПВП ( $r s=-0,49 ; p<0,05)$, прямую среднюю с ИP ( $r s=0,45 ; p<0,05)$, выше средней с АЛТ ( $r s=0,61$; $\mathrm{p}<0,05)$ и Гамма-ГТ ( $r s=0,69 ; \mathrm{p}<0,05)$ и сильную с ТГ ((rs=0,88; $\mathrm{p}<0,05)$.

ВЫводы: кардиоваскулярный риск у большинства женщин (более 70\%) с ожирением, независимо от возраста, был в норме. У всех обследованных наиболее тесная взаимосвязь индекса висцерального ожирения отмечена с уровнями триглицеридов и холестерин липопротеидов высокой плотности в крови. Более слабая корреляция выявлена с инсулинорезистентностью и трансаминазами крови. У молодых женщин определенное влияние на повышение кардиоваскулярного риска оказывает также индекс массы тела, окружность талии, липопротеиды низкой и очень низкой плотности, уровень глюкозы в крови. Отношение окружности талии к окружности бедер, ЖМ\%, уровень АД на кардиоваскулярный риск у женщин с алиментарно-конституциональным ожирением, как молодых, так и среднего возраста, не влияют. 